\title{
SOCIAL NoRMS, COGNITIVE DisSONANCE AND THE TIMING OF MARRIAGE
}

\author{
ALESSANDRO BALESTRINO \\ CINZIA CIARDI
}

\section{CESIFO WORKING PAPER NO. 2068 \\ CATEgORY 3: Social Protection \\ August 2007}

Presented at CESifo Area Conference on Employment And Social Protection, May 2007

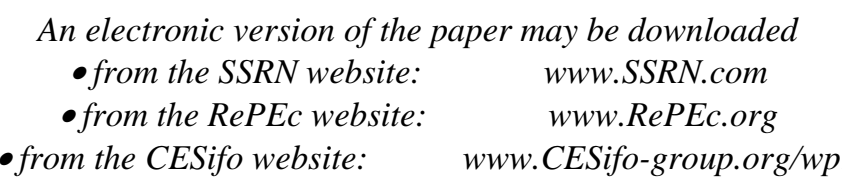




\title{
SOCIAL NORMS, COGNITIVE DiSSONANCE AND THE TIMING OF MARRIAGE
}

\begin{abstract}
We present a model of courtship in which the timing of marriage is affected by the cognitive dissonance between perceived norms and personal aims. We argue that as long as the family has been the main provider of social protection, marriage has been favoured by strongly felt social norms, and thus people accepted less-than-ideal partners early on in their search in order to minimize the dissonance caused by the non-adherence to the custom. Once the Welfare state has replaced the family, these norms have lost their strength, so that agents can afford the luxury of searching their preferred partners at length without feeling at odds with their social duties. The model yields predictions in line with relevant stylised facts: the raising age of marriage, the prevalence of assortative mating and the common occurrence of divorce in the early years of marriage. We finally discuss the impact of late marriages on fertility, and argue that there need not be negative consequences if the declining role of the family becomes socially accepted, and alternative arrangements are made possible and indeed encouraged by means of an appropriate family policy.
\end{abstract}

JEL Code: J12, J13, J18.

Keywords: marriage, cognitive dissonance, fertility.

\author{
Alessandro Balestrino \\ Department of Economics \\ University of Pisa \\ via Serafini 3 \\ 56126 Pisa \\ Italy \\ balestrino@sp.unipi.it
}

\author{
Cinzia Ciardi \\ University of Florence \\ Italy - Florence
}

July 20, 2007

A previous version has been presented at 2007 CESifo Area Conference on Social Protection and Employment, May 18-20, Munich; T. Blumkin, D. Anderberg and A. Casarico provided useful remarks. We also thank J. Ermish and L. Danziger for helpful discussions on the subject matter of the paper. 
It's a question of lust, it's a question of trust, it's a question of not letting what we've build up crumble to dust; it is all of these things, and more, that keep us together...(DEPECHE MODE)

\section{Introduction}

A relevant stylised fact about family formation that is being increasingly confirmed empirically is that the age at which people marry has increased in recent times. This phenomenon is prominent in western societies, although it is by no means limited to those. ${ }^{1}$ To make just one example, consider the UK. Data concerning England and Wales show that the percentage of women marrying (for the first time) before age 20 was around $30 \%$ in the '60s and the '70s, fell sharply to about $13 \%$ towards the end of the ' 80 s and then to less than $5 \%$ in the '90s, to reach an all time low of slightly more than $3.5 \%$ in 2003. Corresponding (rounded) figures for men are $9 \%, 4 \%, 1.5 \%, 1 \%$. In the same time interval, the mean age at first marriage has risen from 23.1 to 28.9 years for women, and from 25.6 to 31.2 for men. ${ }^{2}$ Relatedly, cohabitation has increased; for instance, the percentage of women aged 20-24 in living-in partnerships who were co-habitating without legal marriage has gone from $11 \%$ to $55 \%$ in the years between 1980 and 1995 (Ermish and Francesconi, 2000).

A typical economist's reaction would be that of describing this phenomenon as the result of a changing balance between the benefits and costs of marrying. One of the most widely acknowledged rationale for family formation is the enjoyment of goods and services provided within the family; many of these, in particular, fall into the category of household public goods, which are excludable and rivalrous across families, but fully available to all member within each family. A short list of family-provided commodities is given in the quote at the beginning of the paper; to be more exhaustive, we may mention intangible goods like love and companionship, tangible ones like children, a vast array of services that members provide reciprocally like mutual insurance and intergenerational care, and, importantly, the entitlement to several government

\footnotetext{
${ }^{1}$ For example, it has been noted already a decade ago that in regions as diverse as the Near Est, East Asia, North Africa and Latin America substantially smaller percentages of women married before age 20 than in previous generations (see e.g. Population Reports, vol. XXIII, no. 3, 1995, published by the Johns Hopkins School of Public Health and available at http://www.infoforhealth.org)

${ }^{2}$ These data are from National Statistics Online, http://www.statistics.gov.uk, Table 9.1, and can be retrieved by searching for "age at marriage".
} 
services, like survivors' pensions or family size-related tax cuts. Over the years, the value of most of these internally provided commodities has declined, because other institutions have become capable of supplying suitable substitutes. These institutions are the market and the State, often working together. ${ }^{3}$ An important example of the joint role of the two institutions is associated with the progressive inclusion of women in the labour force. This transformation of the labour market has allowed an increasing percentage of women to be entitled to a pension, and consequently, the value of marriage as a source of income in old age via the husband's pension has decreased. Alternatively, think e.g. of the care of the elderly. In western societies, this service was exclusively provided within the families until not many generations ago (as is provided today in less developed countries); nowadays, there are market services available, and non-negligible forms of public support. Thus, while in the past having children was crucial to one's survival in old age, this is definitely unnecessary these days.

From what we said so far, it seems reasonable to conclude that, in deciding whether to form a couple, the main determinant today must be the perspective to enjoy the intangible commodities (love, companionship, etc.), for which there are no substitutes available outside the family. Of course, legal marriage is unnecessary in this case; the rising importance of cohabitation is in fact consistent with this conclusion. Moreover, there is some evidence from the social psychology literature that in recent years the idea of romantic love as the main factor motivating family formation has become dominant in the Western society: LeVine et al. (1995) have investigated the question whether a young person would marry someone who has all the ideal qualities of partner without being in love, and found that in the US and the UK, only $3.5 \%$ and $3.7 \%$, respectively, of the respondents to the survey would have indeed been willing to do it. Interestingly, the corresponding percentages for India and Pakistan are 49\% and 50,4\%, respectively; this is consistent with the idea that the evolution of marketed and public services in the West has been linked with the decline of the role of the marriage. ${ }^{4}$

The above arguments point out a generic loss of importance of legal marriage. This phenomenon has at least two sides; there are less marriages, and people marry later in life. As

\footnotetext{
${ }^{3}$ An interesting question which we do not develop here is why markets have not been capable of fully supplanting the families in this respect, and strong public action is required. The generic answer is that markets for these services are usually incomplete; for a fuller discussion and more references, see e.g. Cigno (1993) and Anderberg and Balestrino (2003).

${ }^{4}$ The intangible goods "produced" in a marriage (like love and companionship) are rarely given center stage in economic analyses; an interesting exception is Konrad and Lommerud (2006).
} 
hinted at the very beginning of this work, the precise question we intend to study here is why the search for a partner tends to take longer today than in the past. Assuming that two people are suitable for marriage, what determines the length of the time interval during which they manage to know each other sufficiently well to get married?

To the best of our knowledge, there are very few contributions on this subject, mostly based on a beckerian approach in which marriage is viewed as the outcome of a search process: each agent tries to ascertain the characteristics of potential partners in order to secure a suitable match, and when in the end the agent marries, he or she has taken the optimal decision, given the optimally collected amount of information. ${ }^{5}$ In this framework, the timing of the marriage depends on the expected gains as well as on the costs of searching; the focus has been on the role of the former. For example, Keeley (1977) points out that if men have a higher wage than women, gains from marriage stem from the spouses' respective specialisations on the marketplace and at home. Hence, age at marriage for both sexes should increase in the wife's wage rate (and decrease in the husband's wage rate). Bergstrom and Bagnoli (1993) consider a traditional society where men are the bread-winners and women are valued for their domestic abilities; according to their analysis, men marry later in life than women because they need time to build their reputation as high-earners and good providers for the family. Danziger and Nueman (1999) verify both predictions in their empirical analysis of Jews and Moslems in Israel, and also their own hypothesis that marriage age tends to increase in both partners' education.

We attempt here at providing a complementary treatment that investigates how the changing gains from marriage affect the agents' behaviour and motivations during their search. We therefore shift the focus away from the cost-benefit analysis of the outcome towards the costbenefit analysis of the process. ${ }^{6}$ To this end, we rely on the notion of cognitive dissonance, originally due to Festinger (1957) and developed by other scholars (see e.g. Stone and Cooper 2001 for a long list of references) in the field of social psychology. Cognitive dissonance describes the outcome of the psychological discomfort suffered by a person when her beliefs and her actions are reciprocally inconsistent. Indeed, if a person cannot act in accordance with her beliefs or attitudes, she has the option of changing the latter, i.e. of undergoing a process of cognitive

\footnotetext{
${ }^{5}$ The efficient decision-making process that lies at the heart of the beckerian approach has been challenged on many accounts recently: see e.g. Konrad and Lummerud $(1995,2000)$ for a summary of the arguments.

${ }^{6}$ Cameron (2003) emphasizes the role of search in an economic model of divorce. Frey and Eichenberger (1996) argue that high rates of divorce are related to imperfections in the matching process.
} 
adaptation. In a seminal paper, Akerlof and Dickens (1982) study the dissonance between the decision to accept a risky job and the fear of injury; in this case, adapting one's beliefs implies a reduction in the subjective evaluation of the actual risk of being injured. This would justify the existence of norms intended to ensure the safety of workers: the process of cognitive adaptation leads the workers to ignore precautions, so as to support their adapted belief that their job is not so risky after all. ${ }^{7}$ A possible interpretation, in economic jargon, is that the agents' actual choices (behaving riskly) are not in line with their preferences (avoiding injuries). ${ }^{8}$

The paper is structured as follows. Section 2 explains why we believe that the implications of cognitive dissonance for the timing of marriage deserve our attention. In brief, we argue that behaviour concerning marriage is dictated also by social norms, and that an agent's compliance is mediated by the strategies adopted to avoid the dissonance (i.e. the psychological discomfort) generated by behaviour inconsistent with the norms. When the norm supporting the practice of marriage is strong, because marriage is crucial to the survival of the society, people marry early and accept also non-ideal partners, since breaking the norm would be unbearable. When the norm becomes weaker due to the transformation of the economy and the society, personal expectations have more relevance and people take their time to choose the right partner - as staying unmarried or cohabiting are no longer perceived as conflicting with a social custom.

Then, in Section 3, we proceed to analyse an economic model that incorporates a role for cognitive dissonance in the sense just explained. We characterise the choice of a partner as a search process during which people may revise their idea of who is an acceptable spouse: when they fear they will no longer be able to realize a suitable match, they change their attitudes and get married with a less-than-ideal partner. ${ }^{9}$ This strategy change was more frequent and occurred earlier in the past than today, since marrying is less valuable and people feel the tension between expectations and facts less strongly; this then leads to raising the age of marriage,

\footnotetext{
${ }^{7}$ Since Akerlof and Dickens (1982), cognitive dissonance has featured in several economic models intended to explain the behaviour of potential criminals (Dickens 1986), the process of social change (Rabin 1994), the insurgence of the underclass (Oxoby 2004) and a variety of other phenomena.

${ }^{8}$ That choices may be unaligned with preferences is a fact whose relevance has been stressed also in other contexts. For example, Sen (1977), in developing his arguments against the vision of the homo economicus as a "rational fool", notes that when expressing e.g. a vote on the provision of public goods, people may choose something which goes against their own narrowly defined interest if they feel a commitment to do so (e.g. because of social norms).

${ }^{9}$ This modelling strategy has been applied to job search by Goldsmith et al. (2004).
} 
which is in line with the observed empirical patterns. We note that the model predicts imperfect assortative mating, also consistently with observations - see e.g. Ermish et al. (2006). Finally, we use the model to investigate divorce behaviour, and find that it respects the normally observed pattern that divorces tend to occur early on in the marriage (Becker 1991).

Section 4 rounds off the paper with a discussion of the policy implications of the model, with an exclusive focus on fertility. We argue that the societies where the diminishing role of the family has been accompanied with the establishment of alternative arrangements have suffered limited consequences. In particular late marriages have not contributed to the fertility decline. The refusal to accept these alternative arrangements is conducive to sterile actions. Since the agents' reaction to the incentives supplied by the social environment leads them to marry late, it would seem in principle possible to have them marrying earlier by modifying these incentives. However, this cannot be done because the incentives descend from the very process of evolution and transformation of our society.

Finally, Section 5 offers some concluding thoughts.

\section{Cognitive dissonance and social rules for marriage}

We start with a brief description of the phenomenon labelled "cognitive dissonance"; this should pave the way for a proper understanding of the role that this phenomenon may play in an economic theory of marriage, especially in connection with the influence of social customs.

\section{A definition of cognitive dissonance}

According to Festinger (1957), the term refers to the relationship existing between pairs of what psychologists call "cognitions", i.e. notions a person has about herself, her behaviour, the environment in which she lives. These cognitions may have nothing to do with each other (Festinger's example is that knowing how much it takes for a letter to go from New York to Paris is totally unrelated to knowing that hot and dry weather is good for maize plantations in Iowa), but they may also be linked, either consonantly or dissonantly. ${ }^{10}$

A dissonant relationship between two cognitions $a$ and $b$ is established when, taking the two in isolation, non- $a$ follows from $b$. Thus, for example if we see a person whom we know is

\footnotetext{
${ }^{10}$ As Stone and Cooper (2001) point out, contemporary research in psychology views primarly dissonance as a function of cognitions concerning behaviour, rather than just any pair of cognitions as in the original Festinger's framework. This is however in line with the economists' usual perspective.
} 
in a bad financial situation with a new expensive car (again Festinger's example), we face two dissonant cognitions. Cognitive dissonance is a persistent state of affairs, because everything we do involves a great number of cognitions and it is most likely that at least one will be inconsistent with another. ${ }^{11}$ However, in most cases, the dissonance will be negligible; it will only be felt when the inconsistent cognitions refer to something extremely valuable for the agent, when the action to take or not to take has consequences that are important and/or difficult to assess, when there are irreversibilities, etc. Thus, choosing which type of ice-cream to have after dinner is not a decision in the same league as establishing whether to marry or not, and with whom. In fact, "making a difficult and irrevocable decision" is one of the behavioural actions typically studied in social psychology when testing the existence and relevance of cognitive dissonance (see e.g. Knox and Inster 1968).

An important distinction, based on the source, is between "nomothetic" and "idiographic" dissonance (Stone and Cooper, 2001). The dissonance is called nomothetic when it is generated by the presence of cultural and social customs, whereas it is called idiographic when it is related to individual-specific cognitions. The distinction matters when it comes to identifying the strategies that can be followed to minimise the discomfort caused by the dissonance. In principle, the choice is between three options:

- avoiding the dissonance by not performing the action leading to it;

- reducing the dissonance by changing the environment, i.e. by removing (some of) the circumstances that induce dissonance:

- "solving" the dissonance by changing one's own opinions about the circumstances that cause it, i.e. by changing one's subjective evaluation of these circumstances.

We expect the agent to choose the least costly option.

In the case of nomothetic dissonance, changing the environment is normally unfeasible: if a social custom is in place, a single individual can do nothing to change it. Also, there are little resources available to the individual for self-justifying the discrepancy between her behaviour and the norm; one feels uncomfortable for falling short of the internalised rules of conduct, and may exposed to external sanctions (e.g. social stigma). It therefore difficult to modify one's

\footnotetext{
${ }^{11}$ It is worth emphasising that the perception of dissonance is very sentitive to circumstances; eating with one's hands is dissonant with one's knowledge of accepted behaviour in the Christ Church hall at Oxford, but may cause no dissonance somewhere else (or, for that matter, it might have not caused it in another time).
} 
beliefs in order to make them consistent with one's actions. The best option is normally to avoid the source of the dissonance - that is, to follow the custom.

On the other hand, in the case of idiographic dissonance, there might be some very limited degree of control over the environment, inasmuch as the source of the dissonance is specific to the agent and not generally active for all members of the society. More importantly, there are usually resources available for solving the dissonance: if a person feels that she has done well, in terms of personal and societal standards, on many accounts, she can cope more easily with the discomfort caused by one dissonant situation, and adapt her own beliefs. ${ }^{12}$ If one can avoid the dissonance at no cost, that would of course be preferable, but if that option is ruled out for some reason, the best option is normally to solve the dissonance.

\section{Marriage and social customs}

In the not so distant past of the Western societies, say until the late '60's or early '70's there were strong social norms favouring marriage (as there are today in the rest of the world). This comes as no surprise; norms have the primary duty of ensuring the survival and the flourishing of the group (here, the society at large), and as long as the family plays such a key role, by providing a wealth of commodities to its members, social customs supporting it are bound to arise and be established. People will learn as children what is expected from them, and then teach the appropriate behaviour to their children, and thus the norm perpetuates itself. The view of social norms as devices to favour the development of the group in which they exist is well established in the literature (see e.g. Akerlof 1980, Lindbeck et al. 1999). However, while this literature is mostly concerned with the endogenous formation of the norms, here we are interested in the influence of the social custom on individual behaviour, and thus we take the custom itself as given. ${ }^{13}$

The presence of strong norms dictating a certain type of behaviour is a possible source of cognitive dissonance for the individual. If she chooses to remain unmarried, she will violate the norm, and experience a conflict between her action and the perceived normative standard: a

\footnotetext{
${ }^{12}$ Typically, the cognitive change is supported by the establishment of an "information filter", an attitude that the agent takes of systematically ignoring, discarding or criticising all pieces of information that go against his new belief. We do not model the information filter device explicitly; see Gilad et al. (1987) for an attempt at doing exactly that.

${ }^{13}$ Endogenous formation of social norms is investigated e.g. by Dufwenberg and Lundholm (2001) and Falkinger (2004).
} 


\begin{tabular}{|l|l|l|}
\hline & marry & stay single \\
\hline \multirow{2}{*}{ traditional society } & $\begin{array}{l}\text { access to social protection } \\
\text { possibility of idiographic CD }\end{array}$ & $\begin{array}{l}\text { no social protection } \\
\text { nomothetic CD }\end{array}$ \\
\hline \multirow{2}{*}{ contemporary society } & $\begin{array}{l}\text { access to social protection } \\
\text { possibility of idiographic CD }\end{array}$ & $\begin{array}{l}\text { access to social protection } \\
\text { no nomothetic CD }\end{array}$ \\
\hline
\end{tabular}

Table 1: Available options and their consequences at different times

"nomothetic" dissonance arousal. On the other hand, being forced to marry may also cause a dissonance between one's personal preferences and one's actions, because the partner may turn out to be less-then-ideal: an "idiographic" dissonance arousal. We know that the latter form of dissonance is easier to solve; moreover, the incentives to do so are strong, because having a family is in fact often the only way to access several social protection services. Getting married is thus the best way to minimise dissonance: the agents avoids the nomothetic form and solves the idiographic one.

Over the years, things have changed. Economic growth and social development have allowed a significant and unprecedented rise in living standards, and the creation of the Welfare State, together with the evolution of the market economy, has offered a new source for many services that were once available only within a family - as explained in our Introduction. The value of marriage as the cornerstone of society has declined, and correspondingly, the norms supporting it have become less pervasive. From the point of view of the individual, staying single, or cohabiting, is no longer perceived as a violation of a social custom, and personal expectations or standards have become more prominent in determining marriage decisions. ${ }^{14}$ The source of nomothetic dissonance has vanished, and thus the best strategy is now simply to avoid the idiographic dissonance, i.e. to stay single for as long as it takes to find a suitable partner. Under these circumstances, age at marriage will inevitably rise, as the search will be longer.

By way of summary, we include in Table 1 the options available to the agent in the past and today, and note the expected outcomes; in the next section, we analyse this setup in terms of an economic model of search in the marriage market.

\footnotetext{
${ }^{14} \mathrm{~A}$ possible interpretation is in terms of the pyramid of wants proposed by Maslow (1954); once basic wants, like safety, are satisfied thanks to institutions other than the family, more sophisticated wants, like enjoying the companionship of a good partner, emerge.
} 


\section{A model of marriage}

To begin with, a proviso on the terminology used is in order. Normally, the terms "utility", "preferences" and "choices" are regarded as synonymous in economics. Here, we assign them three different meanings. First of all, there are two levels at which agents in our model can be said to have a preference ordering. In the first sense, they have preferences over their marital status, namely they prefer a "good" marriage to a "bad" marriage to staying single. We shall refer to the numerical representation of this preference ordering as utility, because it reflects what ultimately matters to the agent. However, to generate this ordering, we have to postulate that the agents have a preference ordering at another level, on another set of objects, so that they can in fact distinguish a "good" from a "bad" marriage. This is clearly a preference ordering over potential partners: marrying the best partner gives a "good" marriage, all other partners would yield a "bad" marriage, to varying extents. When we mention an agent's preferences, it is to the ranking of potential spouses that we refer. Finally, there are the actual choices made by the agent, which we said need not reflect the preferences ordering over partners, due to the need to avoid cognitive dissonance.

There are two groups of agents, male and female. Both groups have the same size, normalised to unity, and comprise agents belonging to $T$ different types, numbered 1...t...T. The distinction between types can be drawn along any dimension or combination of dimensions: income, wealth, charm, disposition, and so on. The model is entirely general in this respect. To keep computations simple, we take a uniform distribution of types; there are $1 / T$ agents of each type in each group. We assume that $T$ is a very large number; types are identified on a rather fine scale. Each $t$-agent of the male group ( $t$-man for short) is willing to marry any $t^{\prime}$-woman, for $t^{\prime} \geq t$, and will refuse any $t^{\prime \prime}$-woman for $t^{\prime \prime}<t$. The same holds for $t$-women. Higher types are always preferred: all agents would rather marry a $T$-agent than a $(T-1)$-agent, and so on. At the two extremes, 1-agents would be available for all (although they would prefer a $T$-partner most of all), while $T$-agents would like to marry only $T$-agents. These preferences are taken to be stable; they do not vary over time. However, we allow for the possibility the agents do not marry according to their preferences: for example, a $T$-person may, for reasons to be explained below, accept a "mismatch" with a $t$-person, $t<T$. To fix ideas, we always refer to the searching agent as "she", and the (potential) partner as "he".

Each agent goes through a number of successive rounds of courtship; there will be $R$ rounds, 
numbered $1 \ldots r \ldots R .^{15}$ Like $T$, also $R$ will realistically be a large number; there are many opportunities to meet a person of the opposite gender. For each round in which the agent is not married, she gets utility 0 ; in the round in which she marries, and for each subsequent round in which she stays married, she gets utility 1 if the match is correct and $0<\delta(r)<1$ if it is a mismatch. For simplicity, we take all mismatches to be equally bad, no matter how far is the actual spouse from the ideal one; we allow for the possibility that $\delta(r)$ varies with $r$, e.g. because the hardship of having married the "wrong" person increases over time. Most importantly, we allow for the functional form of $\delta(r)$ to vary depending on the type of society we refer to. In a traditional society $\delta(r)$ will always be close to unity; the agent, having solved her idiographic dissonance, will accept the mismatch as a minor cost relative to the "correct" match. In a contemporary society $\delta(r)$ will be much closer to zero: the agent regards a mismatch as barely superior to staying single, since she has no incentives to solve the idiographic dissonance that she may face in case she marries the "wrong" person.

In the case of mismatch, divorce is possible. In the round in which a person divorces, if there is such an occurrence, and as long as she stays divorced (i.e. does not re-marry), she reverts to utility 0 for each round. Moreover, divorce is costly; there are money outlays and psychological wounds to consider. We measure the cost of divorcing in utility terms, and denote it as $\gamma$; it is incurred in the round of divorce. Also, we assume for simplicity that divorce can occur only once; re-marriage will then also be possible once (but the extension to any number of divorces and re-marriages is in fact straightforward).

Finally, let us emphasize that whenever they meet, the agents fully recognize each other's type. Since we are interested in analysing other issues, we rule out imperfect information.

\section{Expected utility}

Consider now the agent's expected utility. At the first round, she either gets utility 1 with probability $1 / T$ or utility 0 with probability $(T-1) / T$; if unmarried, then at second stage she either gets utility 1 with probability $1 / T$ or utility 0 with probability $(T-1) / T$, and if married she gets utility 1 for sure; and so on stage after stage. Ignoring discounting for simplicity,

\footnotetext{
${ }^{15}$ We assume that the rounds all have the same length. It would be more realistic to assume that they increase in length with time, as the opportunities to meet suitable partners will presumably become increasingly rare as one ages. Introducing this modification would however only make computations more cumbersome, without altering the main insights.
} 
expected utility at stage 1 is then

$$
u^{t}(1)=\frac{1}{T} \sum_{r=1}^{R}\left(\frac{T-1}{T}\right)^{r-1}(R-(r-1)) \simeq \frac{1}{T} \sum_{r=1}^{R}(R-(r-1)),
$$

where the approximation is possible because $(T-1) / T \simeq 1$. Thus, more generally, the expected utility for a person still unmarried at round $r^{\prime}$ is

$$
\left.u^{t}\left(r^{\prime}\right)=\frac{1}{T} \sum_{r=r^{\prime}}^{R}(R-(r-1))\right),
$$

and in particular $u^{t}(R)=1 / T$. We call $u^{t}(r)$ the "continuation utility at $r$ ". In what follows, continuation utility plays a crucial role. Note that

$$
u^{t}\left(r^{\prime}+1\right)-u^{t}\left(r^{\prime}\right)=-\frac{\left(R-\left(r^{\prime}-1\right)\right)}{T} \equiv-d(r) ;
$$

clearly, $d(r)$ is positive and $d(r+1)-d(r)=1 / T$, that is $u^{t}(\cdot)$ is decreasing at a constant pace. In particular, $d(1)=R / T$ and $d(R)=1 / T$.

\section{A benchmark case}

We consider first the benchmark case in which choices are always made according to preferences. There will be $1 / T t$-women searching for each $t$; any $t$-woman has $1 / T$ chances to marry at the first round. If a $t$-woman meets a $t^{\prime \prime}$-man $\left(t>t^{\prime \prime}\right)$ she will not be available for marrying, and if she meets a $t^{\prime}$-man $\left(t<t^{\prime}\right)$ he will not be available. Hence, only meeting a $t$-man will result in a marriage. In the second round, there will be slightly less people searching, for some will be already married: of these, $1 / T$ will encounter a $t$-male and will marry. To be precise, for each type, there will then be $1 / T^{2}$ marriages in the first round; in the second round, only a fraction $(T-1) / T^{2}$ will still be searching, hence, there will be $(T-1) / T^{3}$ marriages; and so on for each following round, according to the general rule $(T-1)^{r-1} / T^{r+1}$. However, since $T$ is large, we can take it that $T-1 \simeq T,{ }^{16}$ so that

$$
m(r)=1 / T^{2} \forall r
$$

\footnotetext{
${ }^{16}$ Alternatively, we could assume that for any couple that leaves the market, an indentical man and an identical woman enter the market. This is the so-called Clone Restriction (Burdett and Coles 1999), a clearly unrealistic but extremely manageable assumption. Since our focus is on the role of cognitive dissonance, it seems acceptable to simplify as much as possible the model in all other respects.
} 
where $m(r)$ is the number of marriages taking place at round $r$. The cumulative number of marriages, still for each type, is then simply

$$
M(r)=r / T^{2}
$$

This readily suggests that all agents would be married at $r=T$. We will assume that

$$
T \geq R
$$

so as to allow for the realistic possibility that not all agents will marry. Agents will keep searching until they are married or the rounds end. Note that (6) implies that $d(1)=R / T \leq 1$ - see above.

Burdett and Cole (1999) point out that a complete characterisation of the market equilibrium in search models like the one adopted here requires identifying a Nash equilibrium for which two conditions hold: i) it describes who is willing to marry whom, and ii) it equalises exit flows and entry rates for each type. The extremely simple structure of the model ensures that each person maximises her own utility whenever she marries, given the strategies of everyone else; thus, we achieve a Nash equilibrium. In fact, the continuation utility of a married person, evaluated at the round in which she marries, say $\rho$, is $R-(\rho-1)$, which exceeds $u^{t}(\rho)$ as defined in (2). Also, since we adopted an assumption equivalent to the Clone Restriction (described in fn. 16) the distribution and number of types does not vary in consequence of the agents' strategies and actions and therefore we trivially satisfy the condition on exit flows and entry rates.

Note that this version of the model leads to perfect assortative mating. The empirical evidence cited in our Introduction supports assortative mating, but, as mentioned, not perfect. In fact, the subsequent version, in which cognitive dissonance is introduced, predicts sorting as a general tendency, not as a universal rule, which is more in line with the stylized facts.

\section{Introducing cognitive dissonance}

We suppose now that some agents may at some stage decide that they will marry also people that they do not find particularly attractive (for the time being, we still rule out divorce); this is necessary to follow the social norm that requires them to marry at an early age.

These changes of strategy may occur in a variety of ways, in the sense that any number of agents for each different type may enlarge their pools of suitable partners to different extents. To make our case, let us focus on a particularly sharp example. Suppose that all $T$-agents may, 
if still unmarried after a certain number of rounds, have the opportunity to avoid the tension between their culturally-mediated expectations (being married) and their current predicament (being single) by deciding to accept, from the next round on, any partner they meet. Thus, if the change of strategy occurs at stage $\bar{r}$, the agent will marry with certainty at stage $\bar{r}+1$, getting with probability $1 / T$ a suitable partner and utility 1 for each subsequent rounds, and with probability $(T-1) / T$ a less-than-ideal partner and utility $\delta(r)$ for the subsequent rounds. Any unmarried $T$-agent will compare the continuation utility from sticking to the course dictated by her preference ordering with the continuation utility from switching to a new strategy meant to avoid dissonance, and will chose whatever action gives her the higher utility. ${ }^{17}$

What is the expected utility of an agent who may at some stage revise her attitudes? In the specific circumstances, we have

$$
\left.v^{T}(1 ; \bar{r})=\frac{1}{T} \sum_{r=1}^{\bar{r}}(\bar{r}-(r-1))\right)+\left(\frac{(T-1)}{T} \cdot \sum_{r=\bar{r}+1}^{R} \delta(r)+\frac{1}{T} \cdot(R-(\bar{r}-1))\right) .
$$

Since $(T-1) / T \simeq 1$, we may write

$$
\left.v^{T}(1 ; \bar{r}) \approx \frac{1}{T} \sum_{r=1}^{\bar{r}}(\bar{r}-(r-1))\right)+\sum_{r=\bar{r}+1}^{R} \delta(r) .
$$

The continuation utility for a $T$-agent after the change of strategy has occurred is simply

$$
v^{T}\left(r^{\prime} ; \bar{r}\right)=\sum_{r=r^{\prime}}^{R} \delta(r)
$$

where $r^{\prime} \geq r$. Thus, the rate of decrease of the continuation utility equals $\delta(r)$. We assume that $v^{T}(\cdot)$ decreases at an increasing pace; the longer a person lives with the "wrong" partner, the more she will suffer from the situation.

We can now perform a comparison between $u^{T}(\cdot)$ as defined in $(2)$ and $v^{T}(\cdot)$. We know that they are both decreasing, and that $u^{T}(\cdot)$ decreases linearly - see (3). Then, it all depends on; i) how quickly $v^{T}(\cdot)$ falls; ii) whether $v^{T}(1,1)$ exceeds $u^{T}(1)$ or vice-versa (to check this, we compare $\sum_{r=1}^{R} \delta(r)$ with $\left.\left.\sum_{r=1}^{R}(R-(r-1))\right) / T\right)$ and iii) whether $v^{T}(R, R)$ exceeds $u^{T}(R)$, (compare $\delta(R)$ with $1 / T)$. There are several cases to consider, some more straightforward then other. In this sub-section, we choose three unambiguous situations; in the next, we deal with two ambiguous ones.

\footnotetext{
${ }^{17}$ The "information filter" we referred to above is implicitly supposed at work here. In order to support her revised belief that it is after all acceptable to marry a non-ideal person, the agent has to manipulate the information she receives from the environment.
} 
- CASE 1: $v^{T}(r, r)>u^{T}(r) \forall r$. Then, the "change" occurs immediately $(\bar{r}=1)$, because the continuation utility from switching to the new strategy exceeds that from following one's preferences already at stage 1 .

- CASE 2: $v^{T}(1,1)<u^{T}(1)$ and $v^{T}(R, R)>u^{T}(R)$. Then, at some stage $\bar{r}>1$, the continuation utility from adaptation will become larger than that from remaining faithful to one's original attitudes; the adaptation will occur at some intermediate round.

- CASE 3: $v^{T}(r, r)<u^{T}(r) \forall r$. Then, the change never occurs, since $v^{T}(\cdot)$ lies entirely below $u^{T}(\cdot)$.

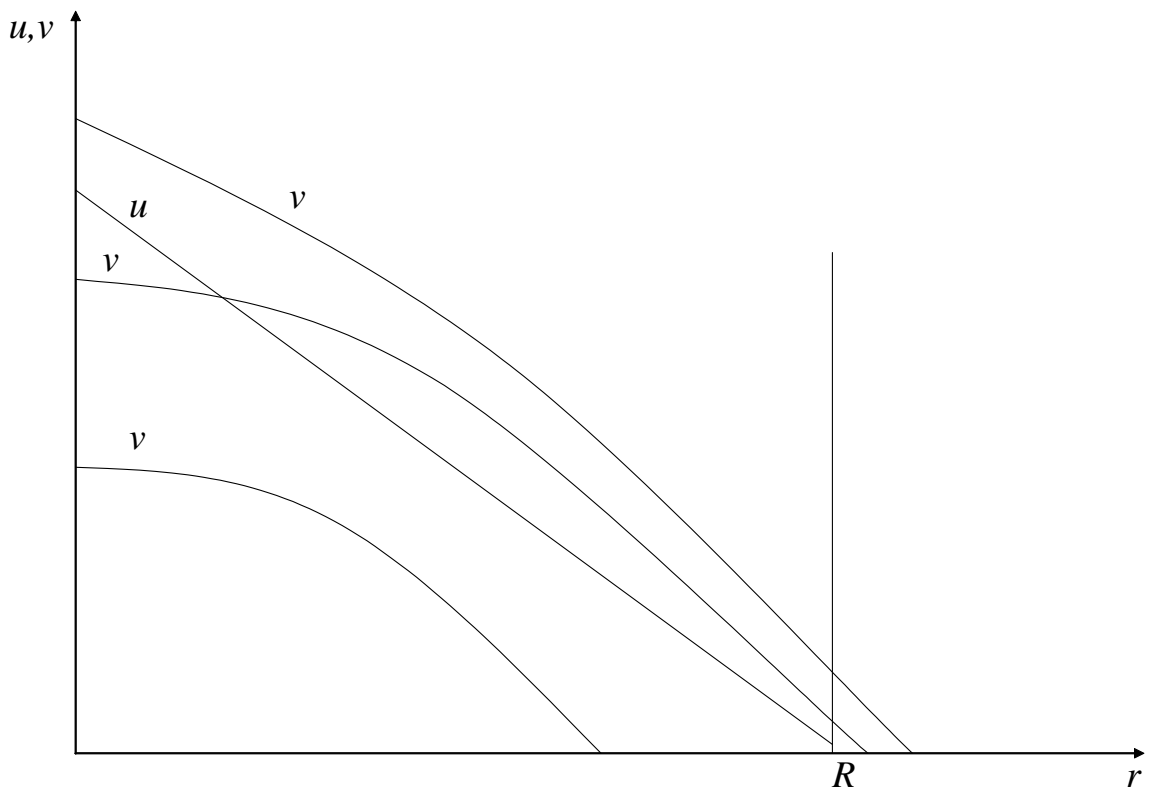

Fig. 1 - The timing of strategy change

These three cases are illustrated in figure 1, where we used continuous approximations to show the pattern followed by the continuation utilities (for $R$ and $T$ "large", this is innocuous). They can be summarised as:

Proposition 1 When the utility from a mismatch is "large", the change of strategy will take place at the first stage:

$$
\left\{v^{T}(r, r)>u^{T}(r) \forall r\right\} \rightarrow\{\bar{r}=1\} ;
$$

when the utility from a mismatch is "intermediate", the change of strategy will take place at some stage after the first:

$$
\left.\left\{\sum_{r=1}^{R} \delta(r)<\frac{1}{T} \sum_{r=1}^{R}(R-(r-1)) \text { and } \delta(R)>1 / T\right)\right\} \rightarrow(\bar{r}>1) ;
$$


when the utility from a mismatch is "low", the change of strategy will not take place

$$
\left\{v^{T}(r, r)<u^{T}(r) \forall r\right\} \rightarrow(\bar{r}=\infty)
$$

\section{Interpreting the analysis}

The message from the above analysis is straightforward: the more adverse agents are to a mismatch, the later a strategy change will occur, and the longer marriages will be delayed. This observation can be made precise by noting how the consequences of cognitive dissonance affects the number of marriages at each round. Quite simply, in the stage when all $T$-agents change their strategies, all $t$-agents for $t<T$ increase their chances to marry: there will be twice as many marriages in that round, $2 / T^{2}$ rather than $1 / T^{2}$, hence, the cumulative number of marriage at $\bar{r}$ will be larger than it would have been without strategy change. The lower is the continuation utility from a change of attitude, the later this jump in the number of marriages will occur. We have considered the limiting case in which only one type of agent may adopt the strategy change. It is however immediate to extend our argument to a case in which more types experience the change; the more types are involved, the stronger is the effect in terms of reduced age of marriage.

Actually, the historical evolution goes, we argued, in the opposite direction. We start from a situation in which many types are affected by the change, and move towards another situation, in which less and less types are affected. Indeed, the case in which the utility of a mismatch is "large" is bound to arise, as we argued, in a traditional society where agents have to avoid the source of nomothetic dissonance and therefore solve the idiographic dissonance. Instead, a "low" utility of mismatches characterises our contemporary society in which agents have no pressure from the social norms and can afford the luxury of not solving the idiographic dissonance. Proposition 1 then tells us that we move from a world in which most agents marry early on to a world in which marriages are delayed or never actually take place. The age of first marriage increases and, importantly, also there will be an increasing presence of assortative mating, which is confirmed empirically (see e.g. Mare 1991 and Jargowsky 1996 on the increase of marital sorting in recent decades). 


\section{Introducing divorce}

So far, we have not allowed for the possibility that a match is dissolved by divorce; we now introduce this extension briefly (most details are omitted since the reasoning follows closely the one in the preceding sub-section).

While we do not discuss in this paper the origins and development of divorce, it seems fair to say that in recent years it has become an increasingly common way of solving the problems of a marriage (for an analysis with specific reference to the UK, see Smith 1997, which also includes many useful references). Divorce is in fact less costly today than it was before, say, the 70 's, on all accounts; in most Western countries there is a favourable legislation protecting the weakest partner (usually the woman) so as to ensure a standard of living as close as possible to the one enjoyed during the marriage; there is less social stigma associated with being a divorced person; and so on.

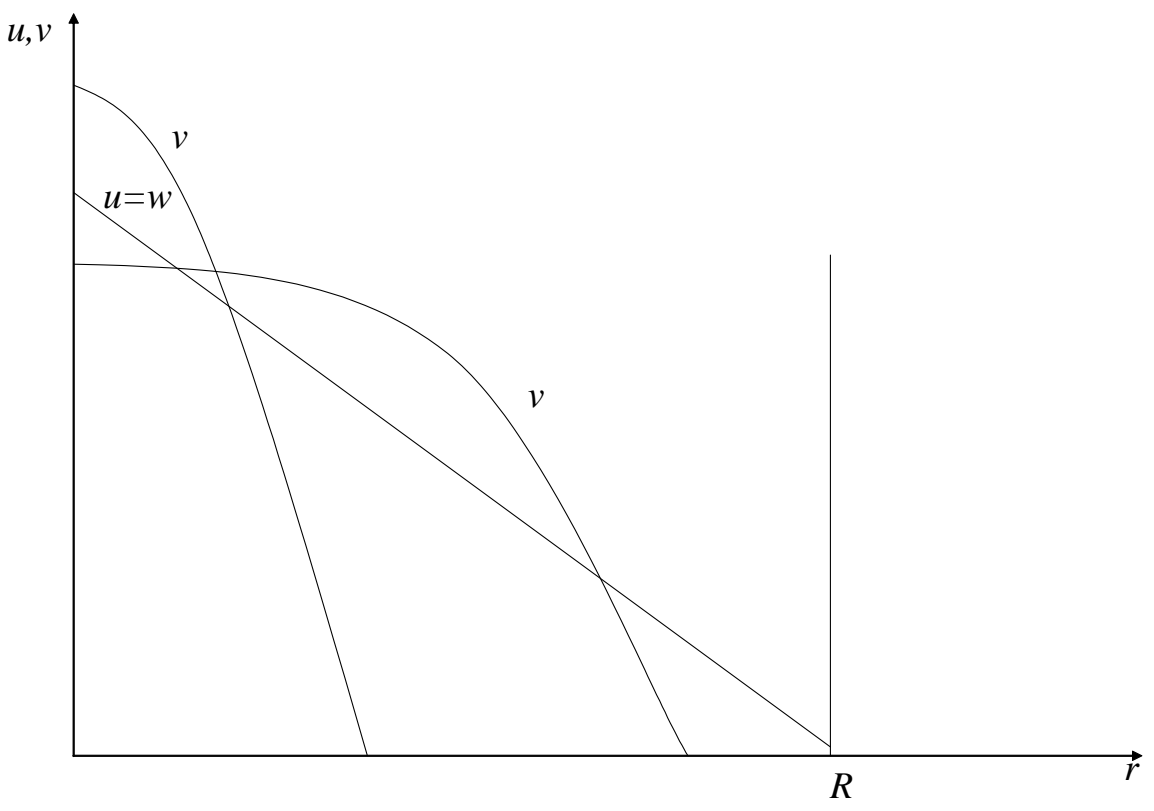

Fig. 2 - Marriage and divorce

Accounting for divorce in case of a mismatch implies basically the possibility to revert to one's preferences if life with the "wrong" person becomes unbearable. Technically, expected utility must be written as

$$
\left.\left.w^{T}(1 ; \bar{r}, \widetilde{r})=\frac{1}{T} \sum_{r=1}^{\bar{r}}(\bar{r}-(r-1))\right)+\sum_{r=\bar{r}+1}^{\widetilde{r}} \delta(r)+\frac{1}{T} \sum_{r=\widetilde{r}+1}^{R}(R-(r-1))\right)-\gamma(\widetilde{r}),
$$


where $\widetilde{r}>\bar{r}$ is the stage at which divorce occurs. Continuation utility after divorce is thus

$$
\left.w^{T}(r ; \bar{r}, \widetilde{r})=\frac{1}{T} \sum_{r}(R-(r-1))\right)-\gamma(\widetilde{r})
$$

All "mismatched" agents will compare the continuation utility from staying married, $v(\cdot)$, with that from divorcing and starting again the search for a suitable partner, $w(\cdot)$, and choose the best course. This is shown in figure 2 for $\gamma=0$; there, we consider two more cases.

- CASE 4: $v^{T}(1,1)>w^{T}(1)$ and $v^{T}(R, R)<w^{T}(R)$. Strategy change occurs immediately, but is followed by divorce soon after, as the utility from the mismatch falls faster that that from waiting for a correct match.

- CASE 5: $v^{T}(1,1)<w^{T}(1)$ and $v^{T}(R, R)>w^{T}(R)$ but $v^{T}(r, r)<w^{T}(r)$ for some $r$. The adaptation sets in after several rounds, and then is followed by divorce a few stages later.

It is clear that a positive $\gamma$ would delay the age of divorce; in fact, in figure $2, w^{T}(\cdot)$ entirely overlaps $u^{T}(\cdot)$, but with $\gamma>0$, there would be a jump downwards whenever the divorce takes place, and from that round on $w^{T}(\cdot)$ would lie below $u^{T}(\cdot)$, decreasing at the same pace. Since we argued that $\gamma$ has decreased in recent years and that the utility of a mismatch will fall more quickly, the model predicts an increasing number of divorces over the years and a tendency to divorce early on in the marriage; this is in line with the empirical evidence we cited in our Introduction.

\section{Policy issues}

The postponement of marriage may have negative consequences on population growth, as older women and men are clearly less fertile (for women fertility reaches its peak around the age of 20, then starts declining linearly). As it is well-known, a low fertility rate has several adverse effects, most notably on pay-as-you-go pension systems and more generally on the financial stability of the Welfare State. It therefore makes sense to act against any factor contributing to a reduction of fertility, including late marriages.

Of course, in themselves, late marriages need not damage the fertility rate. Like most other goods once enjoyable only within a marriage, children are now affordable also for single mothers and of course for cohabiting couples. Indeed, if couples tend to have children only once they're married, then a raising age at first marriage will definitely contribute to the reduction 
of fertility; but if childbearing is common also outside marriage, the impact will of course be less significant. In an illuminating analysis of out-of-wedlock births in England, Ermish (2006) provides the following impressive figures: for more than a century before 1960 (to be precise, from 1845) childbearing outside marriage had been stable at a mere 5\%, but after 1960 it began to increase, at first slowly, and then more quickly, to reach a remarkable $42 \%$ in 2004 . We may conjecture that this powerful rise in the percentage of children born outside the marriage has been key in avoiding an excessive fall of the fertility rate in England, which has been around 1.7 since 1995 (OCSE, 2006). In fact, pairing these data on bastardy with those on the age at first marriage and cohabitation reported in the Introduction, we see that the changes occurred in a predictable sequence: after 1960 people started to marry later and then both cohabitation and non-marital child-bearing increased.

In other societies, the postponement of marriages has had much more drastic consequences on fertility. Italy is especially worth mentioning, not only for reasons of personal competence of the authors, but because it is perhaps the most striking example. With a dismal fertility rate of 1.2-1.3 in the years from 1990 to 2003, a mean age at first marriage of 31,26 years for men and 28,49 years for women in 2001 (ISTAT, 2005), Italy is paradigmatic of the demographic crisis of the Western societies. The tendency to marry late has taken root in Italy as well. That was hardly avoidable, since the major factors behind these phenomenon, like the social security coverage and the presence of women in the labour market, have been at work. Unfortunately, this has not resulted in a vast increase in cohabitation, which continues to be negligible, but in a longer permanence within the original family. ${ }^{18}$ This implies that the enjoyment of household goods like children is usually postponed after marriage (less than $14 \%$ of children were born outside marriage in Italy in 2004 - see ISTAT, 2005). But since marriage occurs relatively late, it so happens that the period of life when is biologically optimal to have children does not coincide anymore with the period in which people are interested in having children. On the contrary, the current situation in Italy is one in which the fertility peak for women comes at an age when economic independence has not been achieved, and an autonomous family has not been created. This causes an additional strain on fertility, coming on top of the usual disincentives that the modern society offers (e.g. the fact that the value of children as means of support for one's old age is diminished by the presence of social security).

\footnotetext{
${ }^{18}$ Manacorda and Moretti (2006) report that more than $80 \%$ of Italian aged 18-30 lived with their parents in the 1990's. The corresponding figure in the same period for England is about $50 \%$.
} 
It would be tempting to think that a remedy against the negative consequences of late marriages is to establish a policy favouring early marriages. This is however a very conservative and possibly quite ineffectual proposal. Very conservative because it refuses to see that marriage is increasingly less important; quite ineffectual because the subject that should be responsible for devising the policy lines, i.e. the Welfare State, is in fact the single most important factor behind the very problem it should address. We saw that, by making the social customs in favour of early marriages redundant, the Welfare State started the process leading to the prevalence of late marriages today. We would have then a case of an institution trying, as it were, to undo with one hand what it is doing with the other. It is difficult to imagine a government suggesting that, in order to favour early marriages and thus stimulate fertility, women should be discouraged from entering the labour force.

As the above discussion suggests, a different and promising strategy would be that of lowering the costs of non-marital childbearing, namely by favouring cohabitation. A very simple and effective way of doing this is to avoid benefits that apply only to married couples. Again Great Britain is a good example, as this is the direction in which the family policy has recently taken. Italy has instead maintained a very conservative attitude in that cohabiting couples are de facto discriminated; they cannot access public resources devoted to the families as these are often reserved to married couples, they face several administrative and legal difficulties if they want to secure the rights of their children, etc. Powerful pressure groups, like the Catholic Church, are radically opposed to any change of policy in this respect. In fact, the greater incidence of cohabitation in the UK relative to Italy can be interpreted, at least in part, as the outcome of a rational response to policy incentives. Cohabitation could offer a simpler alternative to marriage in terms of family formation, but in order to better perform that role, it should be supported by active government policies, and not hampered by legal restrictions.

Indeed, favouring cohabitation could be more effective than other, traditionally advocated, policies for increasing fertility. For example, promoting immigration flows from ethnic groups in which large families are common rarely works in the medium run. It is well-know that second-generations immigrants tendentially assume the fertility behaviour typical of the host country, rather than retaining that of the origin country (which of course makes perfect sense as a rational response to the actual incentives they face). Also, the practice of favouring artificial techniques for starting pregnancies, may not be particularly effective. These procedures are very costly: apart from the direct outlay in medical services, medicines, etc., there is an opportunity 
cost of foregone income (due to absences from work and more generally reduced productivity). The latter in particular can be relevant, because the period when a couple faces these attempts at starting a pregnancy is very hard on the personal lives of both the woman and the man (see e.g. Beck and Beck-Gernsheim 1995, ch. 4, for a vivid account from a psychological point of view). The partners may well be willing to face such costs, since they may gain access to what is for them a crucially important opportunity, but it is hardly likely that artificially started pregnancies might constitute a socially affordable strategy to boost fertility.

\section{Concluding remarks}

Recognising a role for cognitive dissonance in the decision processes of the economic agents is one of the various steps that can be taken for moving towards an approach that "...incorporates the substantive insights and methodological rigors of economics, while being more realistic about the nature of errors people make..." (O'Donoghue and Rabin, 2003, p. 191). There is in fact a wealth of empirical evidence from the psychology literature (reviewed e.g. in Rabin 1998) that point to the fact that behaviour traditionally deemed "irrational" by economists, like absence of self-control, short-sightedness, choice inconsistency, etc., is systematic rather than occasional.

In this contribution, we have assumed that cognitive dissonance affects the timing of marriage by causing a discrepancy between preferences and choices. In periods when marriage is favoured by social norms people tend to marry early because they choose partners even if they are not the ones they would really prefer to marry; as these norms loose their strength (over time or space), the age of marriage raises because agents become more "choosy". In the passage from a world of binding customs to one of larger freedom, cognitive dissonance is less pervasive, because there is no longer a conflict between perceived norms and personal aims. This mechanism produces predictions which are in line with most stylised facts, not only the raising age of marriage, but also the prevalence (and recent increase) of assortative mating and the common occurrence of divorce in the early years of marriage. We have then employed our framework to analyse the impact of late marriages on fertility, and argued that where the declining role of marriage has been accepted, and alternative arrangements have arisen (either spontaneously or with the help of policy), negative consequences have been negligible. 


\section{References}

Akerlof, G., 1980, "A theory of social custom of which unemployment may be one consequence", Quarterly Journal of Economics, 94, 749-775.

Akerlof, G. and W. Dickens, 1982, "The economic consequences of cognitive dissonance", American Economic Review, 72, 307-319.

Anderberg, D. and A. Balestrino, 2003, "Self-enforcing intergenerational transfers and the provision of education", Economica, 70, 55-71.

Beck, U. and E. Beck-Gernsheim, 1995, The Normal Chaos of Love, Polity Press.

Becker, G., 1991, A Treatise on the Family, enlarged edition, Harvard University Press.

Bergstrom T. and M. Bagnoli, 1993, "Courtship as a waiting game", Journal of Political Economy, 101, 185-202.

Burdett, K. and M. Coles, 1999, "Long-term partnership formation: Marriage and employment", Economic Journal, 109, F307-F334.

Cameron, S., 2003, "The economic role of divorce: the neglected role of search and specific capital formation", Journal of Socio-Economics, 32, 303-316.

Cigno, A., 1993, "Intergenerational transfers without altruism", European Journal of Political Economy, 9, 505-518.

Danziger, L. and S. Neuman, 1999, "On the age at marriage: theory and evidence from Jews and Moslems in Israel", Journal of Economic Behavior and Organization, 40, 179-193.

Dickens, W., 1986, "Crime and punishment again: The economic approach with a psychological twist", Journal of Public Economics, 30, 97-107.

Dufwenberg, M. and M. Lundholm, 2001, "Social norms and moral hazard", Economic Journal, $111,506-525$.

Ermish, J., 2006, "An economic analysis of the history of bastardy in England", mimeo, University of Essex.

Ermish, J. and M. Francesconi, 2000, "Cohabitation in Great Britain: Not for long, but here to stay", Journal of the Royal Statistical Society, 163, 153-171.

Ermish, J., M. Francesconi, and T. Siedler, 2006, "Intergenerational mobility and marital sorting", Economic Journal, 116, 659-679.

Festinger, L., 1957, A Theory of Cognitive Dissonance, Stanford University Press.

Frey, B. and R. Eichenberger, 1996, Marriage paradoxes, Rationality and Society, 8, 187-206. 
Falkinger, J., 2004, "Noncooperative support of public norm enforcement in large societies", CESifo WP no. 1368.

Gilad, B., S. Kaish and P. Loeb, 1987, "Cognitive dissonance and utility maximization", Journal of Economic Behavior and Organization, 8, 61-73.

Goldsmith, A., S. Sedo, W. Darity Jr., and D. Hamilton, 2004, "The labour supply consequences of perceptions of employer discrimination during search and on-the-job: Integrating neoclassical theory and cognitive dissonance", Journal of Economic Psychology, 25, 15-39.

ISTAT, 2005, Matrimoni, separazioni e divorzi - anno 2001, ISTAT.

Jargowsky, P., 1996, "Take the money and run: Economic segregation in U.S. metropolitan areas", American Sociological Review, 61, 984-998.

Keeley, M., 1977, "The economics of family formation", Economic Inquiry 15, 238-250.

Konrad, K. and K.-E. Lommerud, 1995, "Family policy with non-cooperative families", Scandinavian Journal of Economics 97, 581-601.

Konrad, K. and K.-E. Lommerud, 2000, "The bargaining family revisited", Canadian Journal of Economics 33, 471-487

Konrad, K. and K.-E. Lommerud, 2006, "Love and taxes", mimeo, Social Sciences Research Center Berlin and University of Bergen.

Knox, R. and J. Inkster, 1968, "Postdecision dissonance at post time", Journal of Personality and Social Psychology, 8, 319-323.

LeVine, R., S. Sato, T. Hashimoto and J. Verma, 1995, "Love and marriage in eleven cultures", Journal of Cross-Cultural Psychology, 26, 554-571.

Lindbeck, A., S. Nyberg and J. Weibull, 1999, "Social norms and economic incentives in the Welfare State", Quarterly Journal of Economics, 114, 1-35.

Mare, R., 1991, "Five decades of educational assortative mating", American Sociological Review, $56,15-32$.

Maslow, A., 1954, Motivation and Personality, Harper \& Row.

Manacorda, M. and E. Moretti, 2006, "Why do most Italian youths live with their parents? Intergenerational transfers and household structure", Journal of the European Economic Association, 4, 800-829.

O'Donogue, T and M. Rabin, 2003, "Studying optimal paternalism, illustrated by a model of sin taxes", American Economic Review Papers and Proceedings, 93, 186-191.

OECD, 2006, OECD Factbook 2006, OECD. 
Oxoby, R., 2004, "Cognitive dissonance, status and growth of the underclass", Economic Journal, 114, 727-749.

Rabin, M., 1994, "Cognitive dissonance and social change", Journal of Economic Behavior and Organization, 23, 177-194.

Rabin, M., 1998, "Psychology and economics", Journal of Economic Literature, 36, 11-46.

Sen, A., 1977, "Rational fools: a critique of the behavioural foundations of economic theory", Philosophy and Public Affairs, 6, 317-344.

Smith, I., 1997, "Explaining the growth of divorce in Great Britain", Scottish Journal of Political Economy, 44, 519-544.

Stone, J. and J. Cooper, 2001, "A self-standards model of cognitive dissonance", Journal of Experimental Social Psychology, 37, 228-243. 


\section{CESifo Working Paper Series}

for full list see www.cesifo-group.org/wp

(address: Poschingerstr. 5, 81679 Munich, Germany, office@cesifo.de)

2004 Harrie A. A. Verbon, Migrating Football Players, Transfer Fees and Migration Controls, May 2007

2005 Helmuth Cremer, Jean-Marie Lozachmeur and Pierre Pestieau, Income Taxation of Couples and the Tax Unit Choice, May 2007

2006 Michele Moretto and Paolo M. Panteghini, Preemption, Start-Up Decisions and the Firms’ Capital Structure, May 2007

2007 Andreas Schäfer and Thomas M. Steger, Macroeconomic Consequences of Distributional Conflicts, May 2007

2008 Mikael Priks, Judiciaries in Corrupt Societies, June 2007

2009 Steinar Holden and Fredrik Wulfsberg, Downward Nominal Wage Rigidity in the OECD, June 2007

2010 Emmanuel Dhyne, Catherine Fuss, Hashem Pesaran and Patrick Sevestre, Lumpy Price Adjustments: A Microeconometric Analysis, June 2007

2011 Paul Belleflamme and Eric Toulemonde, Negative Intra-Group Externalities in TwoSided Markets, June 2007

2012 Carlos Alós-Ferrer, Georg Kirchsteiger and Markus Walzl, On the Evolution of Market Institutions: The Platform Design Paradox, June 2007

2013 Axel Dreher and Martin Gassebner, Greasing the Wheels of Entrepreneurship? The Impact of Regulations and Corruption on Firm Entry, June 2007

2014 Dominique Demougin and Claude Fluet, Rules of Proof, Courts, and Incentives, June 2007

2015 Stefan Lachenmaier and Horst Rottmann, Effects of Innovation on Employment: A Dynamic Panel Analysis, June 2007

2016 Torsten Persson and Guido Tabellini, The Growth Effect of Democracy: Is it Heterogenous and how can it be Estimated?, June 2007

2017 Lorenz Blume, Jens Müller, Stefan Voigt and Carsten Wolf, The Economic Effects of Constitutions: Replicating - and Extending - Persson and Tabellini, June 2007

2018 Hartmut Egger and Gabriel Felbermayr, Endogenous Skill Formation and the Source Country Effects of International Labor Market Integration, June 2007

2019 Bruno Frey, Overprotected Politicians, June 2007 
2020 Jan Thomas Martini, Rainer Niemann and Dirk Simons, Transfer Pricing or Formula Apportionment? Tax-Induced Distortions of Multinationals' Investment and Production Decisions, June 2007

2021 Andreas Bühn, Alexander Karmann and Friedrich Schneider, Size and Development of the Shadow Economy and of Do-it-yourself Activities in Germany, June 2007

2022 Michael Rauscher and Edward B. Barbier, Biodiversity and Geography, June 2007

2023 Gunther Schnabl, Exchange Rate Volatility and Growth in Emerging Europe and East Asia, June 2007

2024 Erkki Koskela and Ronnie Schöb, Tax Progression under Collective Wage Bargaining and Individual Effort Determination, June 2007

2025 Jay Pil Choi and Marcel Thum, The Economics of Politically Connected Firms, June 2007

2026 Jukka Pirttilä and Roope Uusitalo, Leaky Bucket in the Real World: Estimating Inequality Aversion Using Survey Data, June 2007

2027 Ruslan Lukach, Peter M. Kort and Joseph Plasmans, Strategic R\&D with Knowledge Spillovers and Endogenous Time to Complete, June 2007

2028 Jarko Fidrmuc, Neil Foster and Johann Scharler, Labour Market Rigidities, Financial Integration and International Risk Sharing in the OECD, June 2007

2029 Bernardina Algieri and Thierry Bracke, Patterns of Current Account Adjustment Insights from Past Experience, June 2007

2030 Robert Dur and Hein Roelfsema, Social Exchange and Common Agency in Organizations, June 2007

2031 Alexander Libman and Lars P. Feld, Strategic Tax Collection and Fiscal Decentralisation: The Case of Russia, June 2007

2032 Øystein Foros, Hans Jarle Kind and Greg Shaffer, Resale Price Maintenance and Restrictions on Dominant Firm and Industry-Wide Adoption, June 2007

2033 Jan K. Brueckner and Kurt Van Dender, Atomistic Congestion Tolls at Concentrated Airports? Seeking a Unified View in the Internalization Debate, June 2007

2034 Viet Do and Ngo Van Long, International Outsourcing under Monopolistic Competition: Winners and Losers, June 2007

2035 Nadia Fiorino and Roberto Ricciuti, Determinants of Direct Democracy, June 2007

2036 Burkhard Heer and Alfred Maussner, Inflation and Output Dynamics in a Model with Labor Market Search and Capital Accumulation, June 2007 
2037 Konstantinos Angelopoulos, Jim Malley and Apostolis Philippopoulos, Public Education Expenditure, Growth and Welfare, June 2007

2038 Maarten Bosker, Steven Brakman, Harry Garretsen and Marc Schramm, Adding Geography to the New Economic Geography, June 2007

2039 Steffen Henzel, Oliver Hülsewig, Eric Mayer and Timo Wollmershäuser, The Price Puzzle Revisited: Can the Cost Channel Explain a Rise in Inflation after a Monetary Policy Shock?, July 2007

2040 Rosario Crinò, Service Offshoring and White-Collar Employment, July 2007

2041 Carsten Hefeker and Michael Neugart, Labor Market Regulation and the Legal System, July 2007

2042 Bart Cockx and Muriel Dejemeppe, Is the Notification of Monitoring a Threat to the Unemployed? A Regression Discontinuity Approach, July 2007

2043 Alfons J. Weichenrieder, Profit Shifting in the EU: Evidence from Germany, July 2007

2044 Annika Alexius and Bertil Holmlund, Monetary Policy and Swedish Unemployment Fluctuations, July 2007

2045 Axel Dreher, Jan-Egbert Sturm and Jakob de Haan, Does High Inflation Cause Central Bankers to Lose their Job? Evidence Based on a New Data Set, July 2007

2046 Guglielmo Maria Caporale and Luis A. Gil-Alana, Long Run and Cyclical Dynamics in the US Stock Market, July 2007

2047 Alessandro Balestrino, It is a Theft but not a Crime, July 2007

2048 Daniel Becker and Michael Rauscher, Fiscal Competition in Space and Time: An Endogenous-Growth Approach, July 2007

2049 Yannis M. Ioannides, Henry G. Overman, Esteban Rossi-Hansberg and Kurt Schmidheiny, The Effect of Information and Communication Technologies on Urban Structure, July 2007

2050 Hans-Werner Sinn, Please bring me the New York Times - On the European Roots of Richard Abel Musgrave, July 2007

2051 Gunther Schnabl and Christian Danne, A Role Model for China? Exchange Rate Flexibility and Monetary Policy in Japan, July 2007

2052 Joseph Plasmans, Jorge Fornero and Tomasz Michalak, A Microfounded Sectoral Model for Open Economies, July 2007

2053 Vesa Kanniainen and Panu Poutvaara, Imperfect Transmission of Tacit Knowledge and other Barriers to Entrepreneurship, July 2007 
2054 Marko Koethenbuerger, Federal Tax-Transfer Policy and Intergovernmental PreCommitment, July 2007

2055 Hendrik Jürges and Kerstin Schneider, What Can Go Wrong Will Go Wrong: Birthday Effects and Early Tracking in the German School System, July 2007

2056 Bahram Pesaran and M. Hashem Pesaran, Modelling Volatilities and Conditional Correlations in Futures Markets with a Multivariate t Distribution, July 2007

2057 Walter H. Fisher and Christian Keuschnigg, Pension Reform and Labor Market Incentives, July 2007

2058 Martin Altemeyer-Bartscher, Dirk T. G. Rübbelke and Eytan Sheshinski, Policies to Internalize Reciprocal International Spillovers, July 2007

2059 Kurt R. Brekke, Astrid L. Grasdal and Tor Helge Holmås, Regulation and Pricing of Pharmaceuticals: Reference Pricing or Price Cap Regulation?, July 2007

2060 Tigran Poghosyan and Jakob de Haan, Interest Rate Linkages in EMU Countries: A Rolling Threshold Vector Error-Correction Approach, July 2007

2061 Robert Dur and Klaas Staal, Local Public Good Provision, Municipal Consolidation, and National Transfers, July 2007

2062 Helge Berger and Anika Holler, What Determines Fiscal Policy? Evidence from German States, July 2007

2063 Ernesto Reuben and Arno Riedl, Public Goods Provision and Sanctioning in Privileged Groups, July 2007

2064 Jan Hanousek, Dana Hajkova and Randall K. Filer, A Rise by Any Other Name? Sensitivity of Growth Regressions to Data Source, July 2007

2065 Yin-Wong Cheung and Xing Wang Qian, Hoarding of International Reserves: Mrs Machlup’s Wardrobe and the Joneses, July 2007

2066 Sheilagh Ogilvie, 'Whatever Is, Is Right'?, Economic Institutions in Pre-Industrial Europe (Tawney Lecture 2006), August 2007

2067 Floriana Cerniglia and Laura Pagani, The European Union and the Member States: Which Level of Government Should Do what? An Empirical Analysis of Europeans' Preferences, August 2007

2068 Alessandro Balestrino and Cinzia Ciardi, Social Norms, Cognitive Dissonance and the Timing of Marriage, August 2007 